\title{
Continuous Assessment In Schools: Teachers' Bitter Pill To Swallow
}

\author{
Mutendwahothe Walter Lumadi, University of South Africa, South Africa
}

\begin{abstract}
This paper articulates debates surrounding the concept of Continuous Assessment (CA) in South African schools. Although the research was focused on schools in this democratic country, it became evident from the findings that assessment is still a challenge besetting both General Education and Training (GET)and Further Education and Training Bands (FET) worldwide. One of the fundamental reasons for the previous national disenchantment with regard to summative assessment has been the gross inequities that have resulted from inferences based solely on final examinations. In the post apartheid era, the Department of Education made it compulsory that schools turned to CA that is backed by criterion-referenced standards. CA has been heralded as the solution to a host of education ills, including the apparent gap in performance between students of various political and religious backgrounds.
\end{abstract}

Keywords: Continuous Assessment (CA); Summative assessment; General Education and Training (GET); Further Education and Training (FET)

\section{INTRODUCTION, BACKGROUND AND ORIENTATION}

$\mathrm{n}$ GET and FET schools, interpretations based on a single final examination mark have been used to place students in low track classes, to require students to repeat grades, and to deny grade 12 students cohort university admissions. It goes without saying that the negative personal and societal effects for students are recorded as exposure to an inferior curriculum, high dropout rates, poverty and lives of unemployment. The use of examinations as a tool for selecting students for access to educational and economic opportunities is antithetical. It is imperative to point out that in the National policy on assessment; teachers assess the curriculum as implemented in the classroom. They have an opportunity to modify their pedagogical strategies to include construction of remediation activities for learners who are not copying with the expected grade level and the creation of enrichment activities for learners who are working above the expected grade level.

In 1993, a public outcry from responsible parents, guardians and sponsors of children about the Summative Assessment was registered to the Ministry of Education. This form of assessment had its own shortcomings. One pitfall is that it assumes that the same tool can assesses all students fairly. This assessment is norm referenced, and it measures students' test performance against the performance of other students. Furthermore, students happen to do well during the course of the year, but fall ill toward examinations and, as a result, fail to have a thorough preparation or do not seat for the end-of-year examinations. The semester mark was not taken into account when the student's verdict was taken. This had a negative repercussion of failing their final examinations dismally which had to be written over a short period of time. The grade 12 student cohort could not get matric exemptions that would enable them to get university admissions. This was a fundamental issue that had been bothering various stakeholders since time immemorial.

\section{THE CONCEPTUAL FRAMEWORK UNDERPINNING THE STUDY}

According to the World English Dictionary (2009), CA is defined as assessment of student's progress based on work they do or tests they take throughout the term or year rather than on a single examination. The Cambridge dictionary online (2010) views it as the system in which the quality of a student's work is judged by various pieces of work during a course and not by one final examination. The former Minister of Education, Naledi 
Pandor, after consultation with the Council of Education Ministers and in terms of section 3(4)(1) of the National Education Policy Act, 1996 (Act No. 27 of 1996), read with section 6(A) of the South African Schools Act, 1996 (Act. No. 84 of 1996), published the National Policy on Assessment and Qualifications for Schools in the General Education and Training Band in the Schedule for general information.

\section{RESEARCH DESIGN}

The research was conducted in KwaZulu Natal (KZN) which is one of the nine provinces in South Africa (refer to Figure 1).

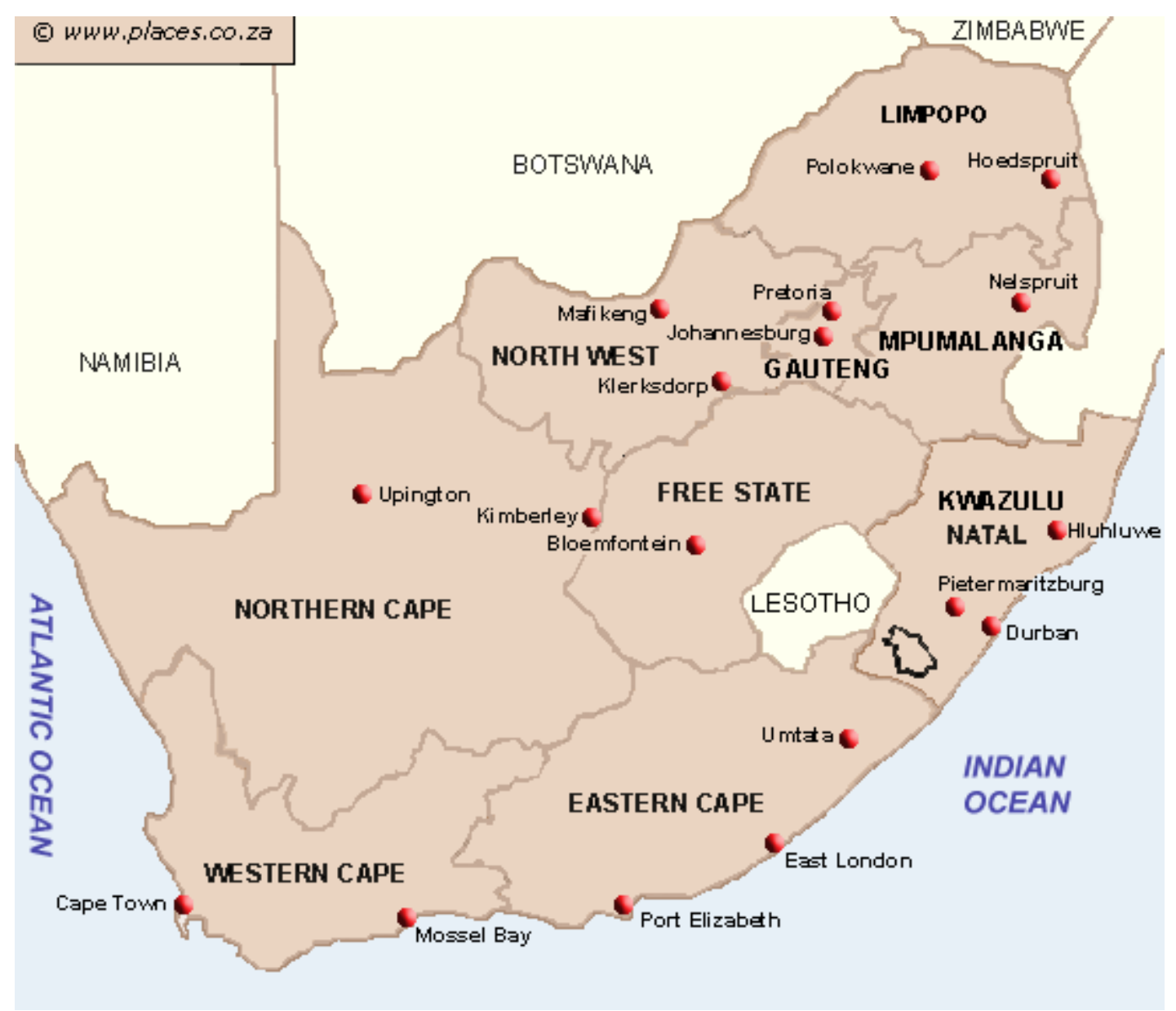

Figure 1: Map of South Africa with its 9 Provinces

KZN consists of various districts, and the researcher has chosen the Umlazi district, formerly known as Durban South. The Circuit office of the Department of Education in Umlazi district provided the statistics and identified schools that were worth visiting. Four of the well-known townships were selected; namely; Umlazi, Amanzimtoti, Lamontville, and Chatsworth. Two high schools from each township were purposefully sampled on the basis of their grade 12 results for the past three years (functional and dysfunctional). Sixteen teachers were randomly sampled from a population of 1,644. Four teachers - two male and two female - from each school represented eight schools. All interviewees had at least an undergraduate degree, which is a BA, and their teaching experience ranged from 16 to 22 (refer to Table 1 for the respondents from Umlazi district and their details). A mixed method, using both qualitative and quantitative, was suitable for the study. Interviews were employed as research instruments for data collection. 
Table 1: Respondents from Umlazi District

\begin{tabular}{|l|c|c|c|c|}
\hline Township & Umlazi & Amanzimtoti & Lamontville & Chartsworth \\
\hline Schools & 2 & 2 & 2 & 2 \\
\hline Teachers & 4 & 4 & 4 & 4 \\
\hline Experience & 18 & 16 & 20 & 22 \\
\hline Qualifications & BAEd & Bed Hons & BA & Bed \\
\hline Gender & M \& F & M \& F & M \& F & M \& F \\
\hline
\end{tabular}

\section{FINDINGS AND DATA PRESENTATION}

In this study, respondents from the four townships in KZN represented a number of distinct, though interrelated, challenges, such as validity and reliability, right of information, feedback, neuropsychological assessment, training, and administration (refer to Figure 2 on findings identified from the study). A brief discussion regarding each of them follows.

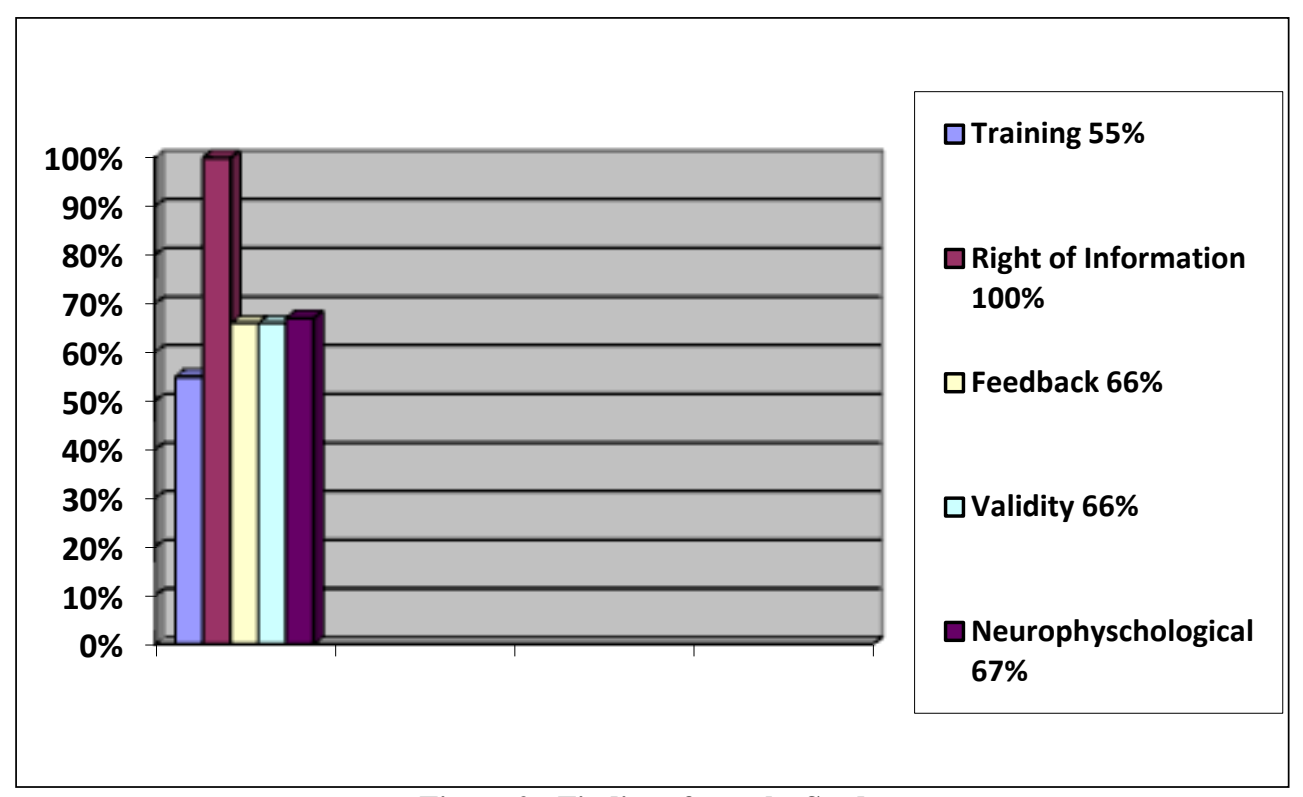

Figure 2: Findings from the Study

\section{Validity and Reliability}

Sixty-six percent of the respondents argued in favour of this challenge. Reliability is the consistency of the measurement or the degree to which an instrument measures the same way each time it is used under the same condition with the same subjects. It is important to remember that reliability is not measured; it is estimated. There are two ways that reliability is usually estimated - retest and internal consistency. Validity is the strength of our conclusions, inferences or propositions. More formally, Cook and Campbell (1979) define it as the "best available approximation to the truth or falsity of a given inference, proposition or conclusion. There are four types of validity commonly examined in social research; namely, conclusion, internal, extract; and external validity. Teachers are supposed to use reliable and valid instruments in testing students. Questions, class work, tests, homework, and projects should measure what they are intended to measure. Each curriculum developer should make a value judgment of the success of the design. CA should enable the teacher to determine to what extent learning has taken place with students (Carl, 2000:127). 


\section{Right of Information}

One hundred percent of the respondents reported that this is a complicated factor (refer to Figure 3 on right of information). Parents and guardians are justifiably concerned that their children be evaluated fairly and appropriately. They have the right to pose the following questions:

- What exactly is the ultimate goal of CA?

- Who is going to assess?

- What are his or her credentials?

- $\quad$ How is CA performed?

- How will the information be used?

- Who will see the assessment results?

- $\quad$ To what extent is the privacy (in case of medical treatment) of their children protected? Any professional performing an educational assessment should be willing to discuss these concerns and to share the results of the assessment and their implications, if ever, with the parent. Parents and guardians, too, should be willing to share with examiners any information that might alter interpretation of the assessment results. However, this does not mean that the right of confidentiality should be jeopardized as it might result in legal implications.

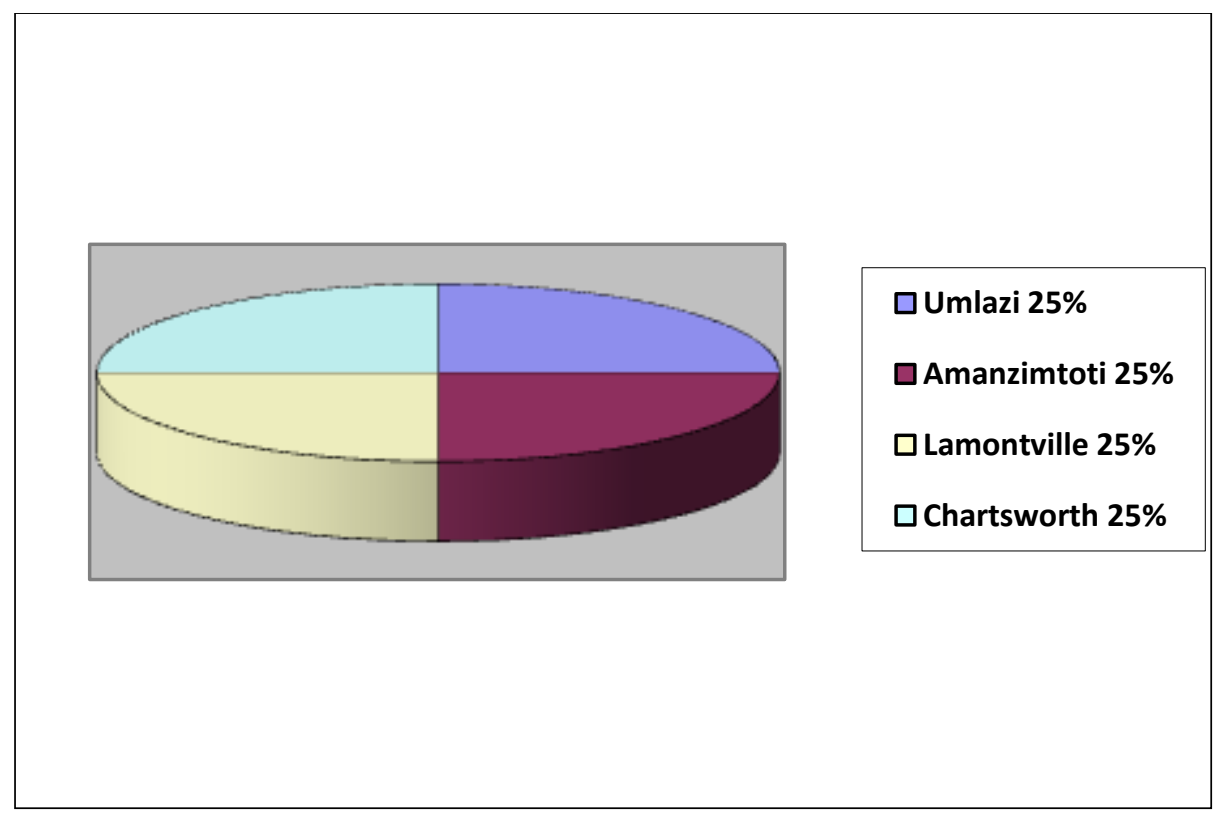

Figure 3: Right of Information

\section{Neuropsychological Assessment}

Sixty-seven percent of the respondents maintained that neurological assessment is a tool for evaluating how much a child's performance may be influenced by unusual functions of the brain and nervous system. It helps school psychologists systematically measure a child's skills and determine the best learning environment for the child (Lezak, 1995). This assessment tool has traditionally been used by hospital clinicians and clinical psychologists. However, now that teachers have begun to recognize the value of neuropsychological assessment, many school psychologists are being trained to use it as a regular part of assessing children with special needs ( Lezak, 1995).

Recently, education experts have begun to use neuropsychology to explain why some children have trouble acquiring language skills, learning to read (especially at foundation level), developing arithmetic reasoning skills, and so on. Using neuropsychology in schools can help teachers serve students with learning disabilities more 
effectively because a student who has neurologically-related disabilities does not benefit from the same teaching techniques of a student who learns at a slower rate. For CA to be a success, both parents and teachers are encouraged to have a mutual working relationship. If a teacher suspects that a student may be having this problem, he should resort to another testing mechanism. If it does not pay dividends, he should refer such a child, with the permission of the parent, to a school psychologist. However, this is a taxing exercise which would require committed teachers.

\section{Feedback}

Sixty-six percent of the respondents indicated that feedback is of vital importance to the learning process. When all students receive their tests and projects, they carefully check for two major things; namely, scores allocated for the piece submitted and comments made by the respective teacher. This is to be encouraged - the provision of as much helpful feedback as possible, in writing, and redirection to support resources and services, as appropriate, is likely to greatly assist learning. Consistency between markers is essential and the use of marking rubrics and guides can help achieve this, as well as provide an outline resource for students of what is required. The turnaround time can encourage or discourage students in South Africa's policy environment. CA has become a weapon of education reform. Curriculum designers and education specialists regard test scores as a measure of educational quality and use test scores to hold schools accountable for teacher performance (O'neil \& kitson, 1999:126).

\section{Training and Administration}

According to Sinclair and Hanks (1989: 853), training is learning or teaching the skills that are needed for the job. CA has to be done meticulously. Fifty-five percent of the respondents are concerned about lack of training from government officials. The training they received was haphazard and no follow-ups were made. Although some of them are highly qualified, they should be empowered with skills that will enable them to face the challenges with ease. Teachers find themselves doing both academic and clerical work. Although learners are supposed to keep their own portfolios, teachers, too, are compelled to have their own updated records. These records are to be kept safe for a certain period of time. This adds more responsibility on their workload. Teachers may object to the additional time necessary for developing and grading performance assessment and may also have difficulty in specifying criteria for judging student work. Teachers need expertise in the curriculum undergoing change (O'neil \& Kitson, 1999:16).

\section{DISCUSSION}

It became evident from the study that there is a parallel debate over the extent to which CA techniques provide adequate information for school accountability. Curriculum developers agree that large-scale assessment instruments alone are not a sufficient basis for evaluating school programs, but rather must be combined with other classroom-based measures to provide an adequate picture of student learning. Furthermore, assessment results must be considered in the context of the resources provided to support instruction. For quality assurance, CA should be planned by an interdisciplinary group that includes assessment experts, curriculum experts, teachers and subject advisors. It is imperative that all parties understand the merits and demerits of CA. Unless instruction and pedagogy is overhauled and opportunities are provided for all students to experience the same demanding curriculum, CA may reveal greater performance gaps than Summative Assessment they replace. Schools may develop and use CA with the expectation that a better monitoring system will address inequitable learning outcomes for students. In actuality, CA must be integrated with curriculum and instructions in order to promote equity in student learning.

The CA policy standard for Grades 10-12 adopts a six-point scale of achievement. The scale is shown on Table 2.

Table 2: Scale of Achievement for the CA Policy Standard on Grades 10-12

\begin{tabular}{|c|c|c|}
\hline Rating code & Description of competence & Marks (\%) \\
\hline 6 & Outstanding & $60-100$ \\
\hline 5 & Meritorious & $50-59$ \\
\hline 4 & Satisfactory & $40-49$ \\
\hline 3 & Adequate & $30-39$ \\
\hline 2 & Partial & $0-29$ \\
\hline 1 & Inadequate & \\
\hline
\end{tabular}


In planning $\mathrm{CA}$, teachers should make use of the following tips:

- $\quad$ Ensure equal curriculum content and coverage in all classrooms

- Develop and enforce classroom-level standards for opportunity to learn

- $\quad$ Be aware of gender bias and fairness in assessing

- $\quad$ Create policies that allow for the blending of professional development and assessment monies so that curriculum, instruction, and assessment can be aligned for all students (Barrington, 1998) questions:

Furthermore, teachers can make use of the following tips to instill active participation when posing

- Avoid labeling students; e.g. the boy with the maroon shirt, the girl with the black jersey. Instead, it is proper that students be called by their names and not even nicknames.

- It is taboo to use derogatory remarks during the presentations; e.g. I cannot expect much from you because you are from an illiterate family. Anyway, I knew that there is nothing to get from your big head. You are an idiot.

- $\quad$ Teachers should make use of open-ended questions and students should be given enough time to respond.

- Teachers should ensure they value all answers. This can be done by non-verbal signals; e.g. a nod or smile as well as through verbal responses using words, such as good, excellent, marvelous, fantastic. Where possible, a gentle pat on the back may be warranted.

- Use 'buzz groups', so named because of the noise they create. Ask small groups of two or three students to undertake a mini-task or brief discussion that will take only a few minutes. Typical examples are reflecting on material covered or brainstorming questions about a topic in progress, or thoughts about a new topic.

- Use the 'think-pair-share' technique, which is also called the 'pyramid' technique. Set a problem, challenge or issue for discussion. Ask the students to think about and then record their thoughts on the issue (think), discuss their thoughts with another student (pair), and then have the pair join with another pair to discuss the issue further. One member of the group of four reports back to the whole group (share) (Barrington, 1998).

\section{CONCLUSION}

From the foregoing discussion, it became evident that if South African schools are to be held accountable for achieving worthwhile results, it is imperative that teachers develop assessment mechanisms that ensure quality in assessing and interpreting student performance. CA should be more than merely an examination at the end of instruction to see how students perform under special conditions; rather, it should be an integral part of instruction that informs and guides teachers as they make instructional decisions. Assessment should not merely be done to students; rather, it should be done for students to guide and enhance their learning. In order to protect students from unfair and damaging interpretations, teachers should be aware of the merits and demerits in using CA practices for high stakes decisions, such as students retention and promotion, which have negative repercussions for the students affected. This will enable teachers to provide sponsors, parents, guardians and curriculum developers with an overall picture of student achievement. Change will occur from a trio of reform initiatives aimed at continuous professional development in curriculum and instruction, improved pedagogy and quality assessment at school level.

\section{AUTHOR INFORMATION}

Professor MW Lumadi is an experienced Curriculum Developer. He has worked at numerous Higher Education and Training institutions in South Africa, such as Westminster College of Education (as Campus Rector), South African College for Teacher Education in Pretoria, University of Venda for Science and Technology (UNIVEN), Kingdom Tabernacle International College (as Dean) and North West University (NWU). Apart from being Director of the school of Postgraduate Studies at NWU, since 2003, he has served on various managerial committees. He was a member of Campus and Institutional Senate, Chairperson of Research, Commissioner of Oaths, and member of Council. Professor Lumadi is an external examiner of the following universities; Botswana, Limpopo, Free State, Johannesburg, Namibia, Nelson Mandela Metropolitan, NWU, Pretoria, Swaziland, Tshwane 
University of Technology, South Africa (UNISA), UNIVEN, Walter Sisulu, Zimbabwe and Zululand. He joined UNISA in 2010 and he is currently Programme Manager for intermediate and senior phase.

\section{REFERENCES}

1. Barrington, E. (1998) Hot Tips for Tutors, Centre for Professional Development, University of Auckland, New Zealand

2. Carl AE. 2000. Teacher empowerment through curriculum development. Theory and practice. South Africa. Juta Publishers

3. Colosi, LA. 1997. The layman's guide to social research methods. Centre for Social research methods

4. Department of Education. Qualifications and assessment. Policy framework. Grade 10 -12. Pretoria: Government printer

5. Groth-Marnat, G 2003. Handbook of psychological Assessment. $4^{\text {th }}$ edition. New York. Wile and sons

6. Lezak, M, D. 1995. Neuropsychological Assessment. 3rd edition. New York: Oxford University Press.

7. O'neil, J. and Kitson, N.1999. Effective curriculum management. New York. Routledge

8. Sinclair, J and Hanks P, 1989. Collins Essential English Dictionary. Glasgow: William Collins Sons \& Co LTD.

9. The Cambridge Advanced Learners 'Dictionary. 2010. Cambridge. Cambridge University Press

10. The World English Dictionary (2009. North America. Bloomsberry Publishing Company

11. Winking, D. 1997. California. Purpose of assessment. North Central Regional Education Laboratory 


\section{NOTES}

